\title{
TRANSVERSE BEAM BREAK-UP STUDY OF SNS SC LINAC*
}

\author{
D. Jeon ${ }^{\dagger}$ and J. Wei, SNS/ORNL, P.O.Box 2008, Oak Ridge, TN37830, USA \\ L. Merminga, G. Krafft, B. Yunn, R. Sundelin, and J. Delayen, JLab, Newport News, VA23606
}

\begin{abstract}
Numerical simulation indicates that cumulative beam breakup (BBU) instability is not a concern to SNS SC linac. First, simulation is carried out for $\mathrm{CW}$ operation mode where the driving harmonics are those with frequency multiples of bunch frequency $402.5 \mathrm{MHz}$. Even when the median HOM frequency is exactly on resonance with multiples of bunch frequency of $402.5 \mathrm{MHz}$, the cavity-to-cavity HOM frequency spread can ensure operation of linac. Second, in the case of pulsed operation mode, additional driving harmonics of $1 \mathrm{MHz}$ and $60 \mathrm{~Hz}$ are added on top of those of $\mathrm{CW}$ mode. The shunt impedance of these additional modes is relatively small. BBU is not a concern also for pulsed mode operation, as is verified for a few most dangerous modes. More systematic analysis of BBU of pulsed mode operation is done by Sundelin et al [1] and presented at this conference.
\end{abstract}

\section{INTRODUCTION}

SNS $\mathrm{H}^{-}$linac is different from highly relativistic electron linacs in that the beam particle velocity is significantly less than the velocity of light $c$. Effects of wake field and bunch energy loss of a beam with $\beta<1$ is relatively unknown. Recently Kurennoy did some calculation on bunch energy loss for particle beams with $\beta<1$ [2]. It is shown that

$$
\frac{k_{s}(\beta, \sigma)}{k_{s}(1, \sigma)}=\exp \left[-\left(\frac{\omega_{s} \sigma}{c}\right)^{2} \frac{1}{\beta^{2} \gamma^{2}}\right] \frac{(R / Q)(\beta)}{(R / Q)(1)}
$$

where $k_{s}(\beta, \sigma)$ is the loss factor of mode s and $\sigma$ is half of rms bunch length of a Gaussian beam. Here $\beta$ and $\gamma$ are relativistic factors, and $R / Q$ is the shunt impedance. For very short bunches, $\exp [\ldots] \approx 1$. And it is a reasonable approximation to use

$$
(R / Q)(\beta)=\frac{2 c^{2}}{\varepsilon_{o} \omega^{3}} \frac{\left|\int_{0}^{l} e^{-i \omega z / \beta c} \frac{\partial E_{z}(0,0, z)}{\partial x} d z\right|^{2}}{\int_{V} E^{2} d V}
$$

for $\mathrm{H}^{-}$(or proton) replacing $R / Q(1)$ of highly relativistic electron linacs.

A study is performed to investigate the effects of HOM (Higher Order Mode) of SNS superconducting (SC) linac on cumulative beam breakup. This is to provide tolerable $Q$ value of HOM and to provide a systematic view of the dependence on parameters involved such as frequency,

*Work supported by the DOE, under contract No. DE-AC0500OR22725 with UT-Batelle, LLC for ORNL

†jeond@ornl.gov
$\mathrm{Q}$ value, R/Q, frequency spread of HOM. For simulation, TDBBU code [3] developed at JLab is used with the relevant input of SNS SC linac.

Fundamental mode frequency of SNS SC linac is 805 $\mathrm{MHz}$ while bunch frequency is $402.5 \mathrm{MHz}$ because beam bunch is in every other bucket. The linac bunch train is $645 \mathrm{~ns}$ long and the gap is $300 \mathrm{~ns}$. And the macro bunch train is $1 \mathrm{~ms}$ long. For example, when $\mathrm{Q}=10^{5}, \omega=2 \pi \times$ $2400 \mathrm{MHz}$ and $\mathrm{g}=302.4 \mathrm{~ns}$, only $2.3 \%$ of HOM field is damped during this 302.4 ns gap because the remaining field is proportional to $\exp (-\omega \mathrm{g} / 2 \mathrm{Q})$. This is a pessimistic condition from the beam breakup viewpoint.

\section{BENCHMARKING}

Benchmarking of TDBBU code is done by repeating the simulation in Gluckstern's paper [4] and by comparison with the analytical theory. The TDBBU simulation has also reproduced the Gluckstern simulation results exactly as is shown in Fig. 1.

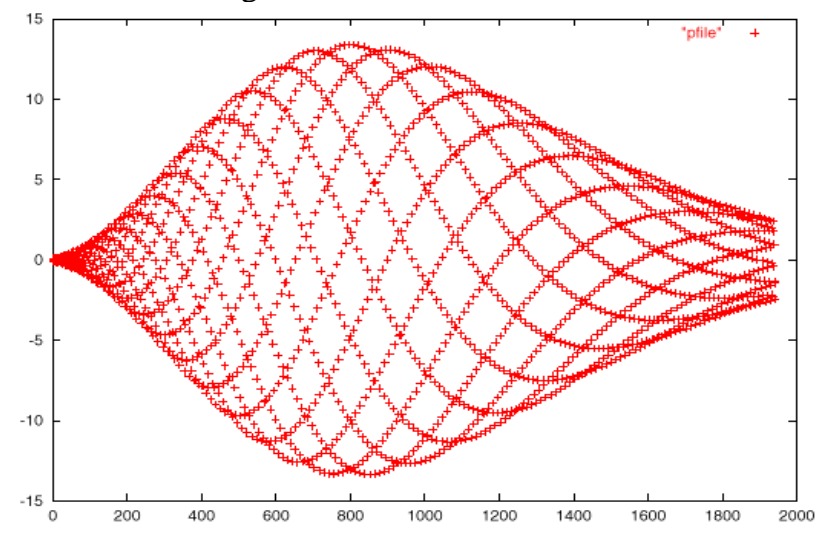

Figure 1: Plot of transverse beam centroid displacement at the end of the linac.

\section{THRESHOLD CURRENT VERSUS Q VALUE OF HOM}

The dependency of threshold current on Q of HOM is studied under pessimistic conditions. In the simulation, all the cavities both in the medium beta section and high beta section are assumed to have the same $\mathrm{f}_{\text {ном }}$ of $2012.6 \mathrm{MHz}$. This is only $0.1 \mathrm{MHz}$ away from the resonance frequency 2012.5 MHz. Threshold beam current is defined as the beam current that produces deflecting factor of 2 at the end of SC linac during $1 \mathrm{~ms}$ beam bunch train. When the deflection factor is larger than 2, beam loss due to the foil miss becomes a concern. The deflection factor $D$ scales as

$$
D \propto \exp \left[\sqrt{I Q_{\text {ном }} R / Q}\right],
$$

where $I$ is the beam current, $Q_{\text {ном }}$ the quality factor of a $\mathrm{HOM}$ and $R / Q$ the shunt impedance. Figure 2 shows 
curves of threshold current for five different values of shunt impedance R/Q.

One interesting fact is that threshold beam current starts to saturate around $\mathrm{Q}=1.0 \times 10^{7}$ for all five values of shunt impedance. Because the "rise time" of the HOM is $1.0 \times 10^{7} /\left(\pi^{*} 2.0126 \times 10^{9}\right) \sim 1.58 \mathrm{~ms}$ for a $2012.6 \mathrm{MHz}$ mode when $\mathrm{Q}$ is around $1.0 \times 10^{7}$. In other words, the instability cannot grow without a long enough pulse for the HOMs to be appreciably excited. When $\mathrm{R} / \mathrm{Q}=100 \Omega$, threshold current of $36 \mathrm{~mA}$ corresponds to $\mathrm{Q}=2.5 \times 10^{7}$. It should be noted that threshold current is inversely proportional to shunt impedance R/Q.

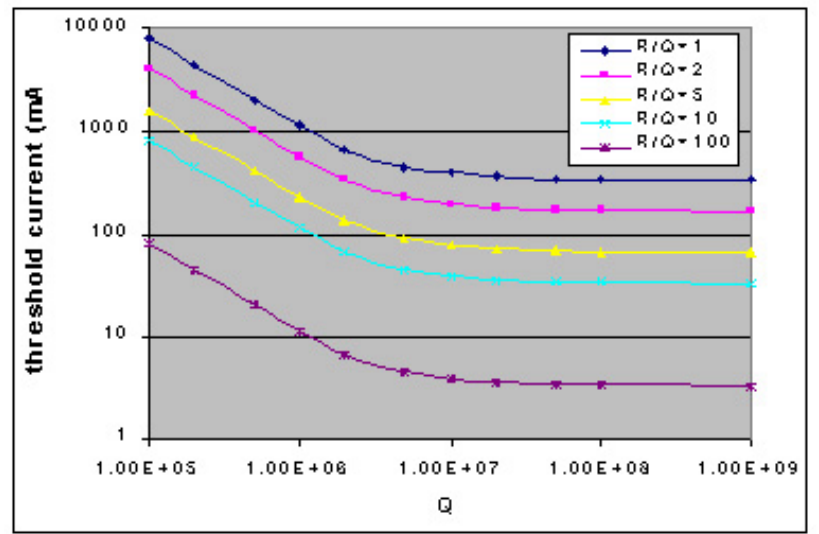

Figure 2: Plots of threshold beam current $(\mathrm{mA})$ versus $\mathrm{Q}$ for different values of shunt impedance $\mathrm{R} / \mathrm{Q}$ in $\mathrm{Ohm}$.

\section{EFFECT OF HOM FREQUENCY SPREAD}

Due to tolerances on manufacturing process of cavities, the frequency of a HOM varies from cavity to cavity. In the case of JLab FEL cavities, cavity to cavity $\mathrm{f}_{\text {ном }}$ ranges from $5 \mathrm{MHz}$ to $30 \mathrm{MHz}$. Cornell data shows that $0.38 \%$ maximum fractional $f_{\text {ном }}$ is measured. This HOM frequency spread effectively reduces the $\mathrm{Q}$ of the mode [5] and increases threshold beam current. In the simulation, $\mathrm{Q}=1.0 \times 10^{7}$ is assumed and shunt impedance $\mathrm{R} / \mathrm{Q}$ is set to $100 \Omega$ for all the cavities and the beam current I to $500 \mathrm{~mA}$, more than ten times of the design current. $\mathrm{Q}=1.0 \times 10^{7}$ is chosen because threshold current starts to saturate from this value. $100-\Omega$ shunt impedance is chosen because MAFIA study [6] indicates that biggest shunt impedance is less than or equal to about 100 $\Omega$. Beam current is set to $500 \mathrm{~mA}$ to allow enough safety factors. One of resonant HOM frequencies is chosen. Median frequency of HOM is set to $2012.5 \mathrm{MHz}$.

Effect of HOM frequency spread is studied for the Lorentzian HOM frequency distribution and uniform HOM frequency distribution. The Lorentzian HOM frequency spread is given by

$$
g(f)=\frac{1}{\pi} \frac{\Delta f}{\left(f-f_{o}\right)^{2}+\Delta f^{2}}
$$

where $f_{o}$ is the median HOM frequency and $\Delta f$ is frequency spread (half-width-half-maximum).

The average deflecting factor versus frequency spread (half-width-half-maximum) in $\mathrm{MHz}$ is displayed in Fig. 3.
HOM frequency spread dramatically reduces average deflecting factor. Average is taken over 1000 Monte Carlo linacs. $3.0 \mathrm{MHz}$ Half-Width-Half-Maximum Lorentzian HOM frequency spread makes linac operation possible even for 500-mA beam current under most severe resonant condition.

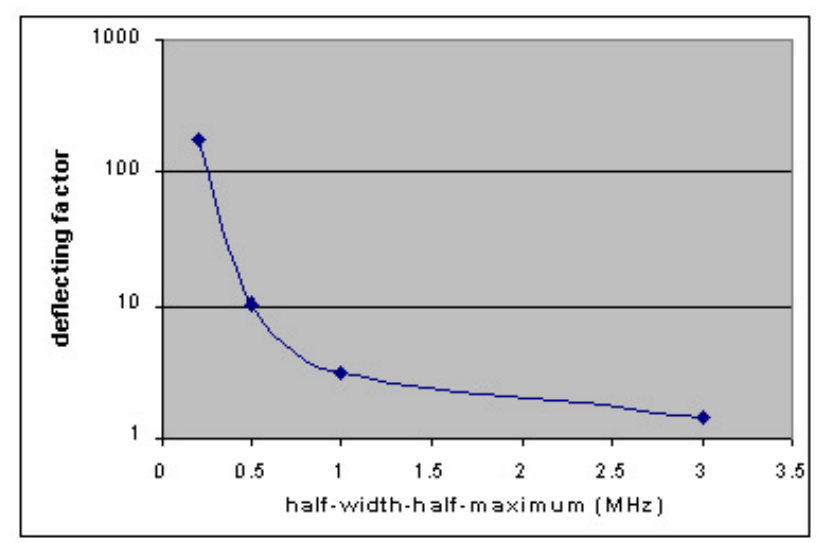

Figure 3: Plot of deflecting factor vs. HWHM (half-widthhalf-maximum) spread of Lorentzian HOM frequency distribution.

\section{EFFECT OF PULSED MODE OPERATION}

There is a $300 \mathrm{~ns}$ gap in every $945 \mathrm{~ns}$ midipulse, which corresponds to $1.058 \mathrm{MHz}$ spectral line. The duration of each macropulse is about $1 \mathrm{~ms}$. The frequency of macropulse is $60 \mathrm{~Hz}$. Preliminary transverse and longitudinal beam breakup simulation is done to estimate the effects of these time structure for a few seemingly dangerous modes. In the simulation presented in Fig. 4, modes listed in Table 1 are taken into consideration. These modes are obtained from MAFIA run. These modes have $f_{\text {ном }}$ quite close to multiples of bunch frequency $402.5 \mathrm{MHz}$ and $\mathrm{Q}$ values are assumed to be $10^{8}$. One monopole mode other than the five-passband modes is taken into consideration. Maximum R/Q value is used for all the cavities instead of energy dependent R/Q values.

Table 1: HOM data used for simulation

\begin{tabular}{lllll}
\hline Cavity & HOM & $\mathrm{f}_{\text {Hом }}[\mathrm{MHz}]$ & $\mathrm{R} / \mathrm{Q}[\Omega]$ & $\mathrm{Q}$ \\
\hline$\beta_{\text {med }}$ & Monopole & 2817.5 & 0.500 & $10^{8}$ \\
$\beta_{\text {med }}$ & Dipole & 1623.9 & 1.680 & $10^{8}$ \\
$\beta_{\text {med }}$ & Dipole & 2021.5 & 3.900 & $10^{8}$ \\
$\beta_{\text {med }}$ & Dipole & 2410.5 & 1.710 & $10^{8}$ \\
$\beta_{\text {med }}$ & Dipole & 2429.9 & 0.195 & $10^{8}$ \\
$\beta_{\text {high }}$ & Monopole & 2817.5 & 0.500 & $10^{8}$ \\
$\beta_{\text {high }}$ & Dipole & 2380.5 & 0.174 & $10^{8}$ \\
$\beta_{\text {high }}$ & Dipole & 2416.7 & 0.361 & $10^{8}$ \\
$\beta_{\text {high }}$ & Dipole & 2818.8 & 0.408 & $10^{8}$ \\
$\beta_{\text {high }}$ & Dipole & 2837.2 & 1.060 & $10^{8}$ \\
\hline
\end{tabular}

All bunches are transversely offset by $1 \mathrm{~mm}$ at injection. Figure 4 shows plots of $\mathrm{x}(\mathrm{mm}), \mathrm{E}_{\mathrm{f}}(\mathrm{MeV})$ and $\phi(\mathrm{deg})$ at the end of SC linac vs. 945-ns long midipulse number over 10 macropulses. Simulation is done with $\pm 0.01 \mathrm{MHz}$ 
and $\pm 0.1 \mathrm{MHz} \mathrm{f}_{\text {ном }}$ spread (monopole and dipole modes, uniform distribution). There is no sign of instability transversely and longitudinally, even though there is some fluctuation. With $\pm 0.1 \mathrm{MHz}$ uniform $\mathrm{f}_{\text {ном }}$ spread (in blue), the fluctuation is already negligible. Even with $\mathrm{Q}=10^{8}$, $\pm 0.1 \mathrm{MHz}$ uniform $\mathrm{f}_{\text {ном }}$ spread is sufficient. In reality, $\mathrm{f}_{\text {ном }}$ spread of other SC cavities is much larger than this. So this BBU issue is not a concern for SNS SC linac.
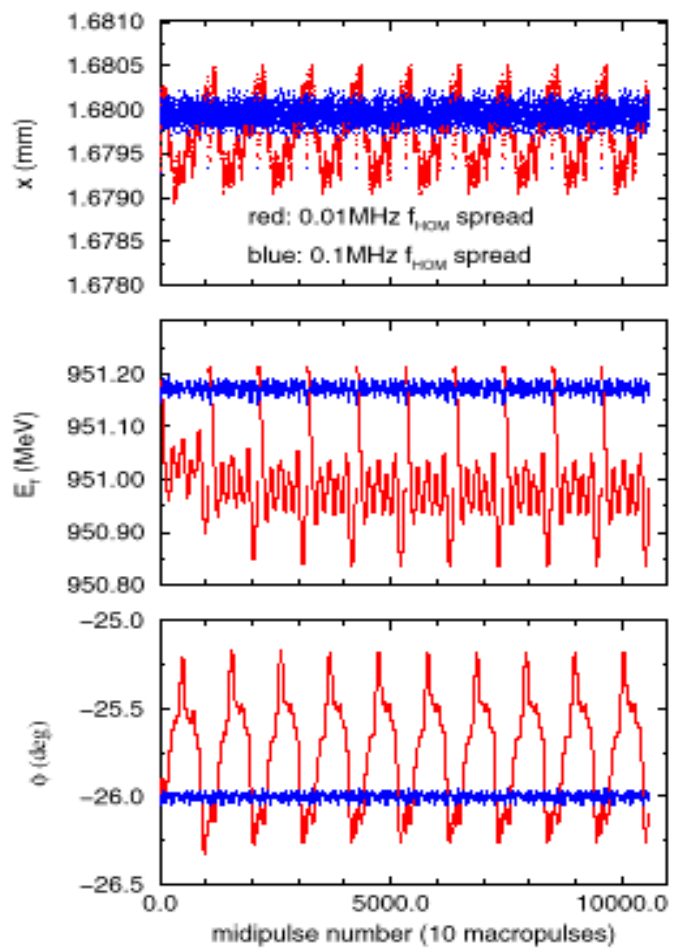

Figure 4: Plots of $\mathrm{x}(\mathrm{mm}), \mathrm{E}_{\mathrm{f}}(\mathrm{MeV})$ and $\phi(\mathrm{deg})$ at the end of SC linac for 10 macropulses. 10 macropulses are clearly shown. The gap is depicted here. With $\pm 0.1 \mathrm{MHz}$ $\mathrm{f}_{\text {ном }}$ spread (uniform distribution), there is no beam breakup instability in both transverse and longitudinal motion.

Now comes the issue of HOM power dissipation in the cavities. Figure 5 shows plots of cavity heat load in $\mathrm{W}$ for the monopole mode in Table 1 for three different values of uniform $f_{\text {ном }}$ spread. This is for one Monte-Carlo machine. Cavity heat load stays below $0.01 \mathrm{~W}$ for most cavities with $\pm 1.0 \mathrm{MHz}$ uniform $\mathrm{f}_{\text {ном }}$ spread. It should be noted that usual $\mathrm{f}_{\text {ном }}$ spread is much larger than the $\pm 1.0 \mathrm{MHz}$ uniform $\mathrm{f}_{\text {ном }}$ spread. Again HOM power dissipation is not dangerous with a sufficient $f_{\text {ном }}$ spread. More systematic analysis of cavity heat load is done by Sundelin [1] and Kim [6]. The cavities with high heat load have $\mathrm{f}_{\text {ном }}$ quite close to resonances.

Figure 6 shows plots of beam energy jitter for three different $\mathrm{f}_{\text {ном }}$ spread vs. pulse number. The beam energy jitter is already less than $0.05 \mathrm{MeV}$ for $0.1 \mathrm{MHz} \mathrm{f}_{\text {ном }}$ spread. Slight spread of HOM frequency dramatically stabilizes the beam.

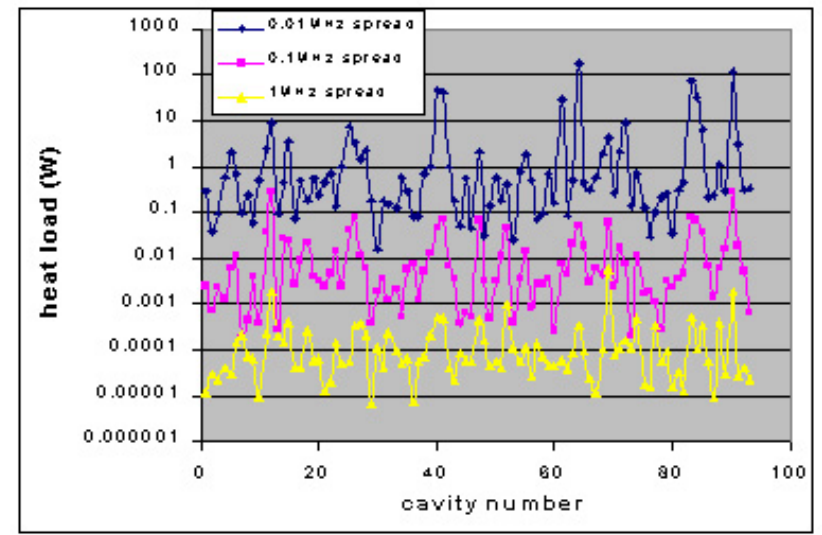

Figure 5: Plots of cavity heat load in $\mathrm{W}$ for the monopole mode in Table 1 for three different uniform $\mathrm{f}_{\text {ном }}$ spread.

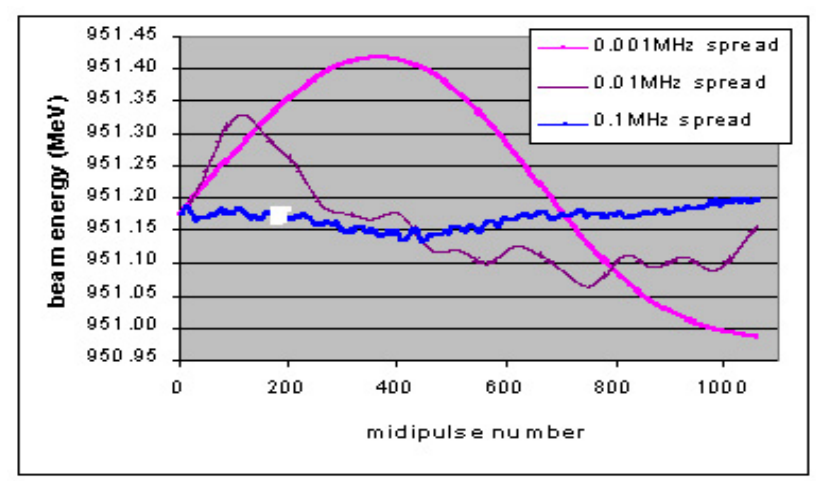

Figure 6: Plots of final beam energy jitter for three different $\mathrm{f}_{\text {ном }}$ spread vs. pulse number.

\section{CONCLUSION}

Study indicates that HOM beam break-up is not a concern even for a pulsed mode operation of SNS superconducting linac. This is mainly due to the HOM frequency spread of cavities due to manufacturing tolerances. Heat load does not seem to be a concern up to $\mathrm{Q}=10^{8}$ with $\pm 1.0 \mathrm{MHz}$ uniform $\mathrm{f}_{\text {ном }}$ spread.

\section{REFERENCES}

[1] R. Sundelin et al, in this conference.

[2] S. Kurennoy, "Dependence of bunch energy loss in cavities on beam velocity", PRST-AB 2, 032001 (1999).

[3] G.A. Krafft and J.J. Bisognano, Two Dimensional Simulations of Multipass Beam Breakup, Proc. of the 1987 Particle Accelerator Conference, 1356 (1987).

[4] R.L. Gluckstern, R.K. Cooper and P.J. Channel, "Cumulative Beam Breakup in RF Linacs", Part. Accel. 16, 125 (1985).

[5] C. L. Bohn and J. R. Delayen, "Cumulative beam breakup in linear accelerators with periodic beam current" Phys. Rev. A 45, 5964 (1992).

[6] S. Kim et al, in this conference. 